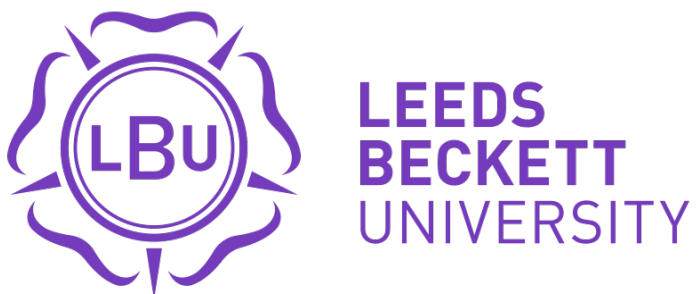

\section{Citation:}

Morgan, J (2015) Is Economics Responding to Critique? What do the UK 2015 QAA Subject Benchmarks Indicate? Review of Political Economy, 27 (4). 518 - 538. ISSN 0953-8259 DOI: https://doi.org/10.1080/09538259.2015.1084774

Link to Leeds Beckett Repository record:

https://eprints.leedsbeckett.ac.uk/id/eprint/2678/

Document Version:

Article (Accepted Version)

The aim of the Leeds Beckett Repository is to provide open access to our research, as required by funder policies and permitted by publishers and copyright law.

The Leeds Beckett repository holds a wide range of publications, each of which has been checked for copyright and the relevant embargo period has been applied by the Research Services team.

We operate on a standard take-down policy. If you are the author or publisher of an output and you would like it removed from the repository, please contact us and we will investigate on a case-by-case basis.

Each thesis in the repository has been cleared where necessary by the author for third party copyright. If you would like a thesis to be removed from the repository or believe there is an issue with copyright, please contact us on openaccess@leedsbeckett.ac.uk and we will investigate on a case-by-case basis. 


\title{
Is Economics Responding to Critique? What do the UK 2015 QAA Subject Benchmarks Indicate? *
}

\author{
JAMIE MORGAN \\ Leeds Beckett University, Leeds, United Kingdom
}

\begin{abstract}
The Quality Assurance Agency for Higher Education provides subject benchmarks which inform but do not determine the content of university and college academic programmes in the United Kingdom. These are revised every few years and have recently been completed in economics for the first time since the global financial crisis. Given the extensive criticism of mainstream economics since the crisis, one might anticipate the benchmark revisions to be extensive. However, this has not been the case. This article explores why this is so. The analysis may also be considered of broader significance because the conditions under which the review has occurred involve general processes that will be familiar, albeit with local variation, to heterodox economists elsewhere. In the conclusion, a more fundamental reconstruction of the benchmarks is provided. These will also be of interest as general orienting statements for a different kind of economics.
\end{abstract}

Keywords: economics education, heterodox economics, pluralism, political economy, realism JEL codes: A11, A12, A20, B50

\section{Introduction}

In January 2015 the United Kingdom (UK) Quality Assurance Agency for Higher Education (QAA) published its consultation document for the subject benchmarks for economics. The benchmarks are reviewed and updated every seven years and provide a guiding reference point intended to inform but not determine the content of university and college academic programmes. A panel of nineteen academics undertook the original formulation in 2000. The

\footnotetext{
${ }^{\ddagger}$ Correspondence Address: School of Accounting, Finance and Economics, Leeds Beckett University, Leeds, United Kingdom LS1 3HE. Email: J.A.Morgan@leedsbeckett.ac.uk.
} 
2014 review group included a panel of ten higher education representatives, two employer representatives and a student reader.

The latest benchmark review document comes at a challenging time for economics. Since the 2008 financial crisis economics has faced significant criticism. The adequacy of economics in general as a body of knowledge, and as a source of training and skills has come into question. It has been questioned in the media, it has been questioned by some of its own most prominent academics, who have supported the creation of a new global foundation (INET 2011), and it has been questioned by its own students who have been motivated to form organizations to shape their own education (see Stockhammer and Yildiz 2015; Beggs 2012). There has been growing concern regarding just what it is economists can claim to know. Whilst there is no doubt that economics furnishes students with skills, there is now growing scepticism regarding the scope and relevance of those skills, and growing concern regarding the further skills that an economics education does not seem to provide. It may be that the absence of those further skills contributes to the problems of the skills that are emphasised, and also to the problems of economics as an adequate body of knowledge (Morgan 2014).

The issues that arise are not just UK issues. They may take a specific form in the UK but there are general processes at work. For example, Colander and Klamer's now classic investigation at elite universities within the United States (US), 'The making of an economist' (Colander and Klamer 1987; Klamer and Colander 1990) highlighted a host of attitudes and practices that have, to greater and lesser degree, become familiar in many countries. Most notably the overwhelming emphasis placed on mathematical training, skills and forms of expression, and hence minimal emphasis placed on acquiring a comprehensive grasp of real economies. At this time there was genuine concern amongst US elite universities that economics was in danger of evolving itself towards extinction. This prompted the American Economic Association to commission a more thorough inquiry into the state of economics education, the Commission on Graduate Education in Economics (COGEE). The report recognized that:

Some critics of graduate education, including many respondents to the COGEE surveys, argue that our insistence on ever higher levels of mathematics has actually led to shallower understanding of basic economic processes ... Concerns about the absence of an empirical and applied basis in the entire economics curriculum were expressed in the open-ended responses to the questionnaires. Students and faculty both noted the absence of facts, institutional information, data, real-world issues, applications, and policy problems (Kreuger 1991, p. 1044, 1046) 
Despite the concerns raised, the 1990s was dominated by the general growth and dissemination of formalism, and of a tacit split between pure theory and ostensibly theoretically empty or neutral forms of applied economics (see Dow 1997). There was some change in the years just prior to the global financial crisis, as Colander notes in his update to 'The making of an economist'.

students believing that having a thorough knowledge of the economy was very important increased from 3 to 9 percent. Being interested in empirical research also increased significantly in importance, with the percentage finding it very important increasing from 16 per cent to 30 percent (Colander 2005, p. 180).

However, he also noted that:

In effect, students have been prescreened to be comfortable with the mathematics in the program. Similarly, graduate schools know better what they want and select students who are comfortable in the approach that will be taught. However, this prescreening comes at a cost, since it likely eliminates those parts of the applicant pool who rank high on creativity and vision, but who either find the mathematics sterile, or do not have the mathematical ability. Mathematicians often process information differently than other people, and by filtering student through a mathematical screen, one is likely to change the nature of economics, making it harder to replicate creative economists (ibid, p. 194)

So one might note there were some changes of degree rather than fundamental shifts. Colander's focus was on graduate level teaching and its ramifications and was restricted to the US. However, economics departments in many countries take their lead from the US and this has been reinforced by the introduction of standardisations (both formal and informal) through versions of 'quality' assessment for teaching and research output. These standardisations have affected the focus of theory and skills, and so also the curriculum, albeit with local variations (for some relevant issues see: George 2007; the special issue of Journal of Australian Political Economy 75, 2015).

An important question arises here. What difference has the global financial crisis made to the trajectory of economics? An analysis of the QAA benchmarks is a useful way to consider this question.

The QAA review provides an opportunity for the profession in the UK to respond to concerns expressed because of the global financial crisis. It could exhibit one of two tendencies. The review could tend more to an affirmation of the status quo by confirming or emphasising the core of the benchmarks that already exist, whilst providing some minor acknowledgement of 'problems'. Alternatively the review could tend more towards a fundamental revision of the 
benchmarks, where the revision is based on a constructive response to identified 'problems'. The difference between these two tendencies ultimately resides in whether the profession and its representatives accept the validity of recent critique. It is this that shapes the response. The February 2015 QAA press release for the economics consultation document (essentially the new draft benchmarks) gives a strong indication of where the tendency lies. I first consider this in terms of the context of economics beyond the UK QAA and then apply the arising points to the way in which the QAA benchmarks are structured. One can read the issues that arise as of general relevance for the continuing development of the field.

\section{The February 2015 QAA Press Release and Its Implications: How the Benchmarks are Positioned}

Although the February press release is headed 'QAA debate signals fundamental change in the study of economics' the content of the release positions the review response as tending towards the status quo. The release opens with,'The academic study of Economics has been sharply criticised in recent months for perceived failings in the way it is taught in universities and colleges' (QAA 2015a, emphasis added). I have added the emphasis since the term is significant. Perceived implies that the failing is primarily one of image. Critics have failed to understand what economics is actually like and what its educators have been doing. This is more a matter of communication failures than of substance. The further implication is then that economics needs to do a better job of communicating its substance, there are no fundamental problems though there may be a need for greater acknowledgement of those areas that critics have oriented on.

It is worth reminding ourselves here what the core of critique has oriented on in order then to consider issues of 'substance' and response (for example, Lawson 2009; Boyer 2013; Fine 2013; Hodgson 2009). ${ }^{1}$ Much of this is implicit in Colander's investigation and its update, though he is not a critic in quite the same sense (see Colander et. al, 2004; Pressman 2013, p. 539). The core of substantive critique has been that economics focuses too much on a narrow range of technical skills and model building. Whilst contemporary economics is empirical, the sense of what it is to be empirical is highly restricted by a focus on the use of available datasets and then of analytical statistics. Innovations beyond this narrow focus have tended to also have

\footnotetext{
${ }^{1}$ Critics do not necessarily agree on all aspects of the problems and emphasise different elements to different degrees. Critiques then encompass different elements - so the critics referenced here are relevant to all of the points that follow in this section.
} 
a restricted sense of what it means to be empirical. For example, experimental economics tends to be based on the design of highly artificial situations that focus participants on particular decision sets from which inferences are made regarding economic activity in complex social situations. ${ }^{2}$ The underlying implication is that it is possible to create laboratory conditions for human behaviour and there are regularities of behaviour that can be identified through isolation and which will continue to hold beyond the experimental situation. So the primary 'skills' focus of economics is restricted and tends to orient on a narrow range of methods. The narrow focus also means that the idea of theory and hence of economics as knowledge is also highly restricted. For theory to be legitimate it is typically necessary that it be tractable, that it entail some form of demonstration proof (in the symbolic-mathematical sense), that it build outwards from defined economic agents, and that it is referenced to a concept of (dis)equilibrium (see for example, Arnsperger and Varoufakis 2006).

To be clear then, critique has not claimed economics lacks empirical content or intent or that economics lacks theoretical range or innovation. Critique has claimed that the restricted nature of what it means to be empirical, and the restricted sense of what is legitimate as theory, limits the realism of economics and undermines its capacity to be constructively pluralistic and genuinely inter-disciplinary. This is important because it creates context for any consideration of the QAA benchmarks as a response to critique. For critics one cannot fix economics by reaffirming its core commitments and then claiming that economics is already more varied than 'perception' seems to suppose. As will become clear as we proceed, if one translates the reaffirmation and claim, they actually conform to the circumstance that critics argue is already problematic. They are not a sufficient response through review; rather, they are a failure to adequately grasp the nature of the problem. So if we attribute good faith to the authors of the QAA, they may genuinely think there are no fundamental problems or that the response is sufficient. But from a critical standpoint the response is based on a failure to understand the nature of the critique and/or a failure to accept the validity of that critique. Hence the issue is primarily positioned as one of 'perception'.

This should be borne in mind when considering the rest of the 2015 QAA press release and how it positions the benchmarks, as well as the benchmarks themselves. In particular the press release states:

\footnotetext{
${ }^{2}$ One might note that natural and field experiments may be less open to the specific criticisms. There are always degrees of difference and dispute regarding this (see Davis 2006).
} 
The existing guidance was already more pluralistic than was commonly supposed, but this revised statement is explicit in acknowledging the contested nature of economics, and the importance of context and of a critical approach within its teaching. The existing strengths of Economics - such as employing powerful concepts and rigorous data analysis - are reasserted, while more emphasis has been placed on communicating economics to noneconomists (QAA 2015a).

One should also note that there is a curious tension in the way critique of the benchmarks is positioned. If the problem is primarily perception and change can be minor, building from or accommodating economics existing 'strengths', then it seems to follow that critique can be, in the main, put aside because it is ill-informed. The implication seems to be that dissatisfaction with the state of economics is manufactured and in some sense external and those who know economics know it is essentially in good health. Both these implications are dubious.

The scrutiny that economics has come under is not manufactured. The global financial crisis was very real and the absence of realism in economics played a significant role in that crisis and its aftermath in at least five ways. The dominant theorisations of economics served to legitimate policy decisions that led to the lack of adequate oversight, control and intervention in and of the financial system. The absence of an integrated normative approach to economic action in economic theory contributed to a failure to account for and contest unethical and destabilising practices within finance and within corporate activity more generally. The development of financial instruments rooted in economic theory served to create the means for bubbles to be created and for herd and convergent behaviour based on fallacies of composition to occur. The actual activity of economists in the business and policy world as paid consultants and advisors added what retrospectively seems to have been an undue legitimacy to decisions and positions. And, the models and tools economists have mainly depended on for shaping, intervening and anticipating the movements of economies did not prevent the emergence of fundamental uncertainty; quite the opposite, they proved conducive to the creation of a false sense of security, and over-confidence in the explanatory power and predictive potential of the models and tools.

The role of economics in the financial crisis was far more fundamental than merely a transitory and quite specific over-reliance on the Efficient Market Hypothesis, the Capital Asset Pricing Model (and variants), minor yet significant technical failings in the construction of Collateralised Debt Obligations and Credit Default Swaps, or a rather conspicuous omission of money creation in the Bank of England and other central bank Dynamic Stochastic General 
Equilibrium (DSGE) models (for example, Morgan 2009, 2015). It was, and continues to be, a failure of critical context, a failure to adequately explore political economy (rather than to produce a tacitly politicised economics), a failure to learn from history, and a failure to internalise the basic lesson of realism transmitted by history (again see Lawson 2009; Boyer 2013; Fine 2013; Hodgson 2009).

That lesson is always relevant to the present as well as to the potentials from which the future arises - a system is always in process. Even during periods of relative stability the underlying factors (of which there can be many and these can be varied) may be qualitatively changing. A system is potentially unstable and uncertainty is always more of an issue than simple probability in the relative frequency sense (Keynes 1921; Knight 1921). The very existence of rules, habits and customs (as institutions operative in and between organizations) are a tacit recognition of this. Humans are social animals and human society, including an economy, is a constant tension between seeking to develop conditions of behaviour that foster security and stability and the dissolution or failure of those endeavours (as well as deliberate attempts to exploit them or undermine them).

The point to emphasise here is that the specifics of the ways in which economics contributed to the financial crisis emerged from general characteristics of the field. Critique is not manufactured and its significance does not reside solely in the specifics of the financial crisis. Rather, a primary problem is one of the mindset of economists, the narrow sense of method and of theory because it is these that then became manifest in the particular ways economics contributed to the financial crisis. ${ }^{3}$ These problems predate the crisis - one need only consider the limited response in the US to Colander and Klamer in a previous era of recognized concerns. The issues here continue since the mindset provides a main context within which economics is responding to critique, including in the UK through the 2015 review of the QAA subject benchmarks.

Consider the defensive connotations of the focus on 'perceived failings' and consider how critique is positioned by the press release. The sense is given that critics have failed to understand what economics is actually like and what its educators have been doing. Since the state of economics has been questioned in the media, by prominent academics and by students, this seems curious. The externalisation of critique seems to create a basic inconsistency. To what degree is critique ill-informed and to what degree is it external? The implication seems

\footnotetext{
${ }^{3}$ By this I do not mean to imply that the problem is simply attitude - it is disposition created, and reproduced through the structures of the discipline and the further structures that structure the discipline.
} 
to be to a significant degree, whilst any consideration of the actual situation would seem to indicate this is not the case. The tacit effect is to negatively position critique based on who it derives from, despite that the entire point of the periodic QAA is to engage in review, including through consultation.

The media have, albeit sporadically, taken considerable interest in ongoing critique concerning the state of economics. In the UK The Guardian newspaper has published a series of letters, interviews and op-eds on the subject, focused particularly on student movements, as have more specialised outlets such as the Financial Times and The Economist (for example, 2015). In January 2015, BBC Radio 4 (2015) devoted a documentary to the subject. In a more international context, one might point to award winning films such as Inside Job. One can then reasonably suggest the media has not been ill-informed but rather has been keen to be wellinformed and to reflect the concerns of a wide variety of parties. Those parties include prominent academics.

On an international scale the financial crisis has served as the backdrop to well publicised blame swapping between prominent representatives of well-known schools (Massachusetts Institute of Technology (MIT), Chicago and Harvard in particular). But it has also motivated a concern with fundamentals. The creation of the Institute for New Economic Thinking (INET) in 2011 was specifically premised on the need for a large foundation to fund and encourage innovative new research, theory and teaching because of the parlous state of the field and because the current structure of departments and of journal publishing priorities were proving to be impediments to the development of the field, including pedagogically. One might also note that significant organizations and their key personnel have at times recognized the fundamental nature of the problem. As Chief Economist, Andrew Haldane has been instrumental in encouraging new alternative research initiatives at the Bank of England, premised on basic problems with prior use of data and research (its narrowness) (for example, Carney 2015). The critique here could not be considered either ill-informed or external. Rather it tends to confirm the criticisms made by heterodox economists over previous years (for example, Lee et. al 2013; Lawson 2003; Dow, 2012; Dow, 1996; Keen, 2001). ${ }^{4}$

So, neither the media nor academic concerns can be reasonably presented as flowing from a failure to understand what economics is actually like and what its educators have been

\footnotetext{
${ }^{4}$ Note also that at a recent Bank of England event Dave Ramsden, head of the UK Government Economic Service (GES) commented that heterodox economics ought to be supported because it was a source of alternative ideas. This has been somewhat at odds with subsequent comments on the curriculum from the Royal Society and other influential sources (see references to CORE later)
} 
doing. They are not really outside positions in the sense of ill-informed (which 'perception' implies); they are outsider positions in the sense of actively externalised. The positioning is a rhetorical move so the inconsistency is not a simple logical failing; the inconsistency makes sense (qua purpose) even if it seems to be nonsensical. Of course, one might respond that carefully scrutinising a QAA press release for meaning is to read too much into what is simply a quotidian act of communication. But press releases are not thoughtless, and whether carefully crafted or hastily cobbled from authorised comment they are indicative of sentiment. Sentiment derives from context and this is broader than the QAA. Sentiment, in turn, is important because it has consequences. It affects the power asymmetry regarding where legitimate voice resides. This too is important because positioning affects how acknowledgement of problems is heard and how they are potentially incorporated. Given the context and the institutional remit of the QAA the review could not be a simple either/or: 'not listening and no change'. It was always going to be more carefully managed: 'you have had the opportunity to speak and we have heard'.

Hearing, however, is not the same as actually listening. Nor is consultation the same as commitment to change based on consultation. Externalising critique is important as an act here because it is indicative of the way critics are perceived and this is just as important as any issue of how economics writ large has been perceived (see for example, Lee 2012). Though critique of economics has been more prominent in recent years, some sources of that critique have been progressively externalised over decades. To some degree heterodox economics is defined by this oppositional positioning. Many heterodox economists have of course embraced this oppositional position, in so far as it is based on a rejection of the narrowness of method and theory, because both have adverse consequences for economics as knowledge (though there is range here within heterodoxy just as there is range within the mainstream). However, it is one thing to be oppositional within a field and thus have a legitimate voice, it is another to be either defined out, and/or be institutionally and progressively shifted out, of the field, and so be denied a legitimate voice (to be distanced). The very existence of this kind of opposition speaks volumes for the limits to demonstrated pluralism within economics. The QAA is of course not responsible for the status of heterodox economists, but the QAA process reflects and serves to reproduce that status. This brings us back to the issue of the use of 'perceived' and the positioning of critique.

If heterodox economists are externalised one confronts a curious situation in which they are not quite economists. But then what makes an economist, and so one worthy of legitimate voice? Given the way economics is structured as a discipline and based on the very terms of 
what for a critic is critique, but for proponents are 'strengths', it is precisely the narrow focus and limitations of method and theory. So there is a debilitating circular reasoning involved here. Proponents of problematic economics are economists, critics of problematic aspects of economics are less so. This then extends to critique deriving from students. Post-crash and other student movements have been motivated to organize their own alternative education (see Post-crash Economics Society 2014). However, by doing so they necessarily invite contributions from critical thinkers, including heterodox economists, in so far as they wish to broaden the basis of their education by exposing themselves to many competing ways of theorising in economics, and different ways of exploring an economic problem. Here one encounters a sub-set of the above issue of narrowness and externalisation. The mainstream response becomes, 'you are listening to the wrong people, and so are being misinformed. As such, you are failing to fully apprehend the nature and quality of economics.' The corollary (which one hears colleagues state) is that it is only once one has completed a sufficient proportion of an economics education that one will begin to think like an economist and fully appreciate its benefits and strengths' ${ }^{5}$

Consider the nature of the response to students. The first aspect trades on a denial of status. It is not an active engagement, with either students or critics. It is a position that provides a reason not to engage. The test here is the degree to which mainstream economists have attended student-organized events. Moreover, have they, whilst in attendance, been prepared to engage in defence, debate and dialogue? Few have. ${ }^{6}$ The second aspect is more than patronising. As a corollary of the first aspect, it implies that one is simply gullible and easily influenced, such that alternative ideas are a danger to 'right' thinking. Exposure will simply result in uncritical absorption of wrong-headed ideas. But it also centrally involves the translation of an economics education from an invitation to learn to a requirement that one accept indoctrination. One fails to 'get it' because one has not yet had time to be fully transformed by a way of thinking and one is actively resisting the transformation. The test here

\footnotetext{
${ }^{5}$ This is not new and students themselves have recognized it in the past: 'A typical comment of upperlevel students was, "The first two years were miserable. Now it is kind of fun and exciting, but I'm not sure the pain was worth it." ' (Colander 2005, p. 179). Also: 'one student noted that one of the teachers in the first year stated, "I'm not here to teach you; I'm here to brainwash you." The student continued, "And that's been pretty much successful." ' (ibid, p. 187)

${ }^{6}$ I gave a talk at the Boom Bust Boom Bust conference (Manchester, April 2015) organized by Rethinking Economics and Post-Crash, sponsored by INET. Attendees included Martin Wolf, Ha-Joon Chang, Steve Keen and many others. There was a notable absence of interest or engagement from mainstream economists despite that the Royal Economics Society conference was also in Manchester the same week. See http://boombustboombust.com/
} 
is a genuine market of ideas. If the appropriate (mainstream) way of thinking has strengths and benefits wouldn't one want to demonstrate these through defence, debate and dialogue? If not, then the mainstream approach to students tacitly advocates thought control. Remember what the context is here.

Students have been motivated to organize their own education and to argue for alternatives because of dissatisfaction with what they are getting from the mainstream. Students are then motivated to seek out alternatives to broaden their education - they are actively engaging in pluralism and their underlying motivation is to be exposed to many ideas in order to make up their own mind (and more fundamentally learn through practical engagement how to make up their own mind - to be critical thinkers). Yet the situation students then experience is one where the expression of dissatisfaction necessarily defines one as not quite an economist (in terms of possible influences) and not quite an economist (in terms of resisting indoctrination - despite that the terms of the problem of influences is the danger of hapless students being exposed to other ideas, implying that students are simultaneously too gullible and too resistant). So the very drive to be a critical thinker, exposed to many ideas, where one is highly motivated and wants to make up one's own mind, become tacit reasons to categorise you as marginal. Again, this is not the fault of the QAA, but it is curious when one recalls that the 2015 press release positions economics as already pluralist. It also does not bode well for the benchmarks as a means to encourage critical thinking.

So, the real context of the QAA review would seem to be one in which some sources of critique are externalised, rendering the force of any critique deriving from those sources to be distanced. The practical consequence is that it is from the internal position that review proceeds, so legitimate voice begins from within the narrowness of method and theory rather than is being oriented to the narrowness of method and theory. This has clear consequences for the review of the benchmarks since they become then a process of reiteration with some acknowledgement of problems, rather than an orientation on those problems as the basis for reconstruction of the very framework of the benchmarks. Review then tends towards restriction rather than fundamental revision. For this to be so, some or all of the participants in the review need not be aware of this discursive framing; it may simply seem a right and sensible approach based on firm commitments (though this does not preclude also more dubious management of the situation, so purposive may be a relative term, from the broadly discursive to the brute intentional). Power need not concern probity; it need not be aware of the nature and ramifications of that power, though again, it may be. 
To reiterate: the issue for the benchmarks becomes that it is from within the problematic to which critique has been applied, a critique which economics has recently not been able to simply deny because of the financial crisis and its aftermath (though problems are not reducible to that crisis), that the problems are then addressed. The very process of response has, therefore, a likely innate conservativism (a focus on renewing through preservation). One might perhaps counter here that the inferences being drawn denigrate mainstream economics. One could more neutrally rephrase the whole as simply the general tendency of any profession to reproduce itself based on perfectly reasonable organizational and institutional practices, which are little different in economics to those in other disciplines. To some degree this is so. But that does not mean there are no consequences from the way in which the reproduction occurs and it does not mean that economics is exactly like other disciplines. Moreover, a neutral language may simply disguise the otherwise recognized fact that power is always operative. Economics is one of the few social sciences that pays little, if any, attention to this in its formal theory and as a research focus. This is despite economists being amongst the most assertive of social scientists, with a strong sense that they are influential and hence powerful in the world.

Economists seem aware of their power but are reluctant to use the term and tend to resist that its ubiquity extends also to their own conditions. This at the very least renders economics vulnerable to the slide from the recognized existence of power as simply normal to the exercise of power as aberrational. Moreover, one ought to acknowledge that economics is organizationally and institutionally different from other disciplines. A great deal of sociological research has confirmed this, as have many economists (albeit sometimes with humour, for example Leijonhufvud 1973). Marion Fourcade has, with a variety of colleagues, been researching the knowledge structures, influence and self-awareness of economists for many years. Her accumulated work is summarised in a recent Journal of Economic Perspectives essay (Fourcade, Ollion and Algan, 2015). Four main points are made regarding mainstream economists:

1. Economics is relatively insular as a discipline and occupies a dominant position within the social sciences. Economists tend only to reference other economists and focus on a very narrow range of economics journals for citation. The dominance of quantitative approaches, model building and assumptions beginning from methodological individualism make it difficult for economists to collaborate on inter-disciplinary research, except in so far as they impose their own approaches on the subject terrain of those other disciplines.

2. Economics is internally hierarchical in a way that is quite different than other social sciences. Again, citation is paramount, based on particular journals and reflecting the narrowness of 
theory and method; this then impacts on university recruitment of new academics and on the career profiles of existing ones. Norms and practices moreover are more coherent across economics than any other social science. There is a sense of unity of approach not found elsewhere and this is reinforced and reproduced through professional associations.

3. Economists have qualitatively different belief systems to other social sciences. For example, the majority of economists are to the left-of-centre by voting pattern in the US, but economists also self-identify as broadly liberal in terms of the marketization of the state (as a matter of the public good), and tend to respond in ways that emphasise the significance of self-interest and egoism to a greater degree than non-economists. So economics either attracts or creates more self-interested persons (albeit also ones with a sense of public duty).

4. Unlike the other social sciences, economists tend to consider it to be a primary aspect of their role to intervene in public discourse and public policy. The combination of characteristics arising from the first three points means that they tend to do so with a degree of unity and selfconfidence that other disciplines do not.

Fourcade's findings, again, tend to confirm longstanding aspects of the critique of the mainstream. Here one might note the political economy critique of the mainstream's tendency to knowledge imperialism (Fine and Milonakis 2009) and its socio-historical development of a set of framing conditions that place sharp limitations on the mainstream's capacity for both change and pluralism (ibid). One could, of course, respond that the very fact Fourcade is published in the Journal of Economic Perspectives tends to refute that economics marginalizes critique. Moreover, one might also note that the 2015 QAA economics review panel included Wendy Carlin and Alvin Birdi both of who are associated with INET through the Curriculum Open-Access Resources in Economics (CORE) project (see Birdi 2014; CORE 2014). Furthermore, the panel included two representatives of Rethinking Economics, an international network set up in order to 'diversify’ economics (see ISIPE 2014).

However, the publication of Fourcade remains anomalous within economics. The issues and trends she identifies are not refuted simply because research on them is published in a mainstream journal. The act may be laudable but the impact limited, and one may reasonably interpret it as an instance of post-financial crisis recognition in the sense of hearing but not listening. INET involvement in the QAA is likewise not as unequivocally positive as one might at first suppose. Though an international initiative to provide a new curriculum is potentially a significant step forward, based on what has been made available so far there is considerable doubt as to whether that new curriculum is fundamentally different than what already exists. In many respects the new curriculum appears to begin from the same basic 
assumption that is expressed in the QAA press release; the problem is primarily perception and change can be minor, building from or accommodating to economics existing strengths (see Association for Heterodox Economics 2014). As such, the involvement of CORE does not indicate the panel was likely to be predisposed to fundamental change. Rather the presence of CORE participants tends to reaffirm (through capture) that legitimate voice begins from within the narrowness of method and theory.

However, the presence of participants from Rethinking Economics is more equivocal. In one respect the QAA are to be commended for this presence (and likewise also for that of Daniela Gabor). ${ }^{7}$ One might argue that their presence runs counter to the tendency for critical thinkers to be defined out, and/or institutionally and progressively shifted out of the field. It is a recognition that may also play a role in reversing this trend. At the same time their presence is not a guarantor of equality of influence on the subsequent review of the benchmarks. It may simply be a limited exercise in 'you have had the opportunity to speak and we have heard'. Externalisation positions people, and the process can result (and has) in externalisation as a physical process (actual expulsion from economics departments). But it is no less effective when it positions ideas.

The 2015 QAA review is one that has occurred in a context where critique has been externalised and so any process of co-option of critics occurs within a power asymmetry, the very basis of which appears to be that change can be limited because the need for change from what already exists is limited. The common sense of this position is that it is appropriate to think outwards from what already exists, and any changes must be compatible with (rather than transformative for) what already exists. The internal dynamics of the panel need not conform to some notional Habermasian ideal speech situation. ${ }^{8}$

So, one can argue that the context in which the QAA panel have reviewed the benchmarks for economics does not seem auspicious for change, and the QAA press release seems indicative of this. Moreover, the inclusion within the panel of a range of voices does not seem as propitious as it might at first appear. The actual influence of context and inclusion can, however, only really be appreciated when one looks at the benchmarks and it is to these we now turn.

\section{Order, Priority and Omission in the Benchmarks}

\footnotetext{
${ }^{7}$ See Gabor (2014) for some interesting non-mainstream work on central banks and financialisation.

${ }^{8}$ See Lancastle (2015) for comment by the student Rethinking Economics representative.
} 
Let us begin with an orienting point and a general question. The existence of the QAA benchmarks for economics since 2000 did not serve to foster an economics that ran counter to (or in a best possible situation served as a constituent in the prevention of) the financial crisis and its aftermath. The existing benchmarks were part of the general epistemologicalpedagogical (and ultimately ideological) framework in which the crisis occurred. Since the very point of the QAA benchmarks is to reflect (and then reflexively shape) the state of the field this is unsurprising. It is further unsurprising if one considers the context we have previously set out.

Mainstream economics exhibits range and innovation but it is also narrow in terms of what counts as economics (which then affects the range and innovation) and who counts as an economist (which affects legitimate voice and creates power asymmetries). As such the QAA benchmarks have tended to express this narrowness in how the field is shaped. However, the crisis and its aftermath have created a greater pressure on economics to acknowledge and address its problems. If these problems are basic and significant then one would expect fundamental change in theory and in research and an opening up of the field, that is, a reevaluation of the basis of theory, research, and who counts as an economist and on what basis. Given the context we have set out, this would then require an internalisation of the externalised critique. The reasonable question that then follows is: how would one restructure the QAA benchmarks in order that they contribute to a re-evaluation (via the curriculum)? What would one expect?

The first thing one might expect is a complete reconstruction of the introductory statements that set out the nature and context of economics (QAA 2015b, p. 5). The review states that there are changes to this initial section. The section contains five statements and these can be summarised as:

1. 'Economics is the study of the factors that influence income, wealth, and well-being. From this it seeks to inform the design and implementation of economic policy. Its aim is to analyse and understand the allocation, distribution and utilisation of resources and their consequences for economic and social well-being' (QAA 2015b, p. 5).

2. The focus of study is the use of resources and the interaction of economic entities at the macro and micro level based on static and dynamic analysis and where explanations are contestable (due to 'observational equivalence' yet different interpretations). 'It is therefore important that economic phenomena are studied in their relevant historical, political, institutional and international contexts (ibid). 
3. As a social science 'it uses mathematics and statistics ...[and] draws on and influences' (ibid) other social sciences (as well as sciences).

4. An economics education enhances employability in many careers.

5. The 'key intellectual features that characterise the economists' approach' (ibid) are:

a. 'The ability to abstract in order to identify and model the essence of a problem' (ibid).

b. The use of deduction and induction in order to analyse.

c. The ability to process 'qualitative and quantitative data' (ibid).

d. The ability to communicate results to different audiences.

e. 'The ability to think critically about the limits of one's analysis in a broader socioeconomic context' (ibid).

f. The ability to apply findings to policy and assess efficacy.

Note that these five points are not being stated in a vacuum, they are being expressed within the received state of the field and where the benchmarks are already positioned as a review within a field that is essentially in good health (the problem is mainly 'perception'). Do they serve to radically reshape both pedagogy and the range of substantive content of the curriculum? Well, statement 2 explicitly recognizes an economic explanation is contestable and that historical, political, institutional etc context matters. Statement 3 seems to explicitly recognize economics is also inter-disciplinary. Statement 5 makes reference to the use of qualitative data and to critical thinking. Ostensibly these are positive and constructive recognitions. However, consider the statements carefully, and read them as statements based on the existing state of the field. The statements contain no explicit active encouragement of the need for more, better or different forms of theory, research, pluralism or inter-disciplinary activity to which students are then exposed. Rather the actual phrasing and emphasis conditions the whole, and the whole is very clearly a set of minor modifications from within (rather than directed at) the received narrowness of the field.

Let's start with the way 'contested' is conjoined with 'observational equivalence' in statement 2. This is a language that reduces the problem to one of data. It is the language of positivism. It lends itself immediately to the sense we are being alerted to an indeterminacy between interpretations of data constructs, that is, models, and most readily relative frequency approaches (though not just these). The importance of context (political, historical etc) then becomes a way to make sense of model and data differences.

This is a highly restrictive sense of the significance of the historical, political, and institutional, and of the contestation of theory, and, thus, thereafter, any meaning of pluralism. Moreover, though used in the press release, the term pluralism is not used here and so is not 
defined. The inference (based on the conjoining of 'contested' with 'observational equivalence') is that pluralism (as an implicit) is conditioned by the current un-decidability between data-led exercises. So the context is one in which one acknowledges the limits of data based on inherent problems of data - and this is good science and so economics as good science. Pluralism simply becomes the current multiplicity of interpretations of the same data based on the same ways of constructing an empirical problem in economics.

Behind this way of thinking is the reduction of objectivity to a technical issue. This is precisely the mainstream tendency identified by Morgan and Rutherford (1998). It is quite different than a sense that objectivity is a value where one is open to and thus considers many different ways to construct a theory and conduct empirical research, which in turn leads also to different substantive forms of theory and different methods. It is then quite different than a positive statement that pluralism is an important constituent in the vitality of the discipline, where there are many legitimate ways of pursuing an economic problem based on substantively different theoretical approaches, and many methods. It is quite different than an explicit recognition of the need for constructive dialogue between significantly different theoretical approaches, where each is accorded disciplinary status. It is quite different than a positive statement that an understanding of history, politics and institutions places limits on the construction, use and application of all models.

Note here there is no positive recognition of or encouragement of the teaching of a range of schools of thought. Nor is there positive recognition that economics is underpinned by norms and so is fundamentally grounded in a deliberative process, which is irreducibly a matter of ethics (for what else is the implication of an economy re statement 1 and 'social wellbeing'?). Nor is there positive recognition that an economy is embedded in an ecology and faces actual material constraint (see Spash 2013). If one again refers to statement 1 , there is a mere 'allocation' problem although there is reference in the full statement 2 to sustainable development as a dynamic allocation problem. There is, however, no positive recognition that allocation, material constraint, deliberation, and the very existence of institutions and of policy issues necessarily entails a historical system within which an economy has and continues to develop as one possible pathway among many, and so economics is always also political economy. Nor is there found any reference to the importance of the history of economic thought or of philosophy as of equal significance for the broad education of a critically aware economist (expressed then in accordance with statement 5). Nor is there reference to the importance of and legitimacy of many methods (see Lee and Cronin 2015; Olsen 2012; Starr 2014). 
Consider the last point. Economics self-identifies as a science and does so based on its empirical aspects. Yet the primary orienting statements of the benchmarks make no direct reference to the need for economists to seek out and use all relevant methods to investigate an economic problem in the pursuit of an adequate account of some phenomenon; that is, there is no positive statement to encourage a prioritising of realism through many methods. There is simply recognition of the need for students to learn how to use qualitative and quantitative data (with a significant emphasis on mathematical and statistical analysis and modelling the 'essence' of a problem, in statements 3 and 5a-c). So in the absence of positive encouragement and based on the existing state of the field, the benchmarks serve to confirm the a priori commitment to a given way of constructing an investigation which is then accorded legitimate status as economics - and this flows directly from within the narrowness of method and theory we have already set out.

Consider also the further consequences for statement 5e, 'The ability to think critically about the limits of one's analysis in a broader socio-economic context' (QAA 2015, p. 5). Taken in isolation the statement seems constructive. However, following the emphasis and order of priority of statements 1-5 and 5a-c, the statement seems more conditional. If the focus of economics is model building, mathematics and statistical analysis, then the 'intellectual features' that will condition critical thinking will tend to critique the technical limits of given data-led modelling exercises, since it is here that the primary skills of the economist will continue to reside. This then returns one to the issues of 'observational equivalence' and what this suggests about what an economist is being taught that is analysis. This is the reverse of how one might more constructively read statement 5e in isolation. In effect, one’s ability to be critically aware of the limits of one's analysis is itself being limited by the prior commitment to the 'intellectual features' of an 'economists' approach'.

Consider this also in terms of its consequences for economics as constructively interdisciplinary. The statements, taken together, position economics based on the prior state of the field, as a relatively unique approach to the social (based on the way an economy is conceived through economics). This then renders meaningful interchange between disciplines highly problematic, since no other discipline quantifies the world in quite the same way and begins from methodological individualism (to which innovations such as institutions must then be conformed). The very terms of inter-disciplinary engagement are then problematic. Note here the statements contain no positive encouragement that economists can learn to think differently and temper their claims based on interaction with other disciplines (a key aspect of any genuine inter-disciplinary approach in economics; see for example, Reardon et. al 2015). Similarly 
there is no positive statement that it can be tempered by constructive dialogue between different approaches to an economic problem - that are all legitimately economics (a key aspect of any constructive pluralism; see Fullbrook 2008; Mearman et. al 2012; Negru 2010; Dow 2012).

So, if one considers all the points made in the previous section and then what has been noted here, then the QAA benchmarks seem to follow on from rather than contribute to a profound reconsideration of the state of the field. Fundamentally the acknowledgement of economics as 'contested' and the need for it to be critical is clearly limited by what is stated and by what is not. Consider again the statement in the press release:

The existing guidance was already more pluralistic than was commonly supposed, but this revised statement is explicit in acknowledging the contested nature of economics, and the importance of context and of a critical approach within its teaching. The existing strengths of Economics - such as employing powerful concepts and rigorous data analysis - are reasserted, while more emphasis has been placed on communicating economics to noneconomists (QAA 2015a).

One might object here that I am reading a great deal into what are concise statements in the benchmarks. But remember these are not neutral statements; they are intended to express the state of the field and will also be read in terms of the state of that field by economists charged with conforming to and implementing the benchmarks. Order of priority (consider statement 5a-f), a conditioning emphasis and conjunction (consider statements 2 and 3), and omission (simply consider what is not here based on the above) are therefore significant.

A genuine reconstruction of the benchmarks would take as its point of departure the need to actively encourage what has not previously been the case (and explicitly recognize failures, and challenge what has been the case). This would be a more fundamental exercise than some additional recognitions and acknowledgement. This is very clearly lacking in the nature and context section of the benchmarks. Since these then orient the rest of the benchmarks there is a major problem with the way in which the benchmarks are constructed. Without appropriate orientation and based on similar issues of emphasis and priority, the subsequent sections can be no more than reiterations with minor revisions. Moreover, those revisions take the form of additional statement or juxtaposition. Revisions become residuals rather than a coherent and complete restructuring of economics in accordance with critique. This means that, where potentially significant statements are subsequently made, one should carefully consider the degree to which they are likely to result in change.

For example, there is reference in Section 4, Subject Knowledge and Understanding, to 'an ability to select and apply appropriate methods that economists might use' (QAA 2015, p. 
7) and also 'An appreciation of the history and development of economic ideas and the differing methods of analysis that have been and are used by economists' (ibid). And, Section 5, Subject Specific Skills and Other Skills, does make reference to 'knowledge of economic history and case studies, pluralistic perspectives and inter-disciplinary synthesis' (ibid, p. 9). These are, of course, potentially constructive recognitions. However, they run counter to the main construction of the initial nature and context of economics section, and then also to the overwhelming emphasis of the rest of the sections. For example, the Section 5 statement quoted is recognition of what employers of economists value, it is not part of Section 5's list of subject specific skills (see QAA 2015b, p. 9(5.4)) which focus on quantification and data analysis in terms of modelling exercises, and the whole is epitomised by 'Economic reasoning is highly deductive and logical analysis is applied to assumption-based models' (ibid). Section 5 ends with a restatement of the centrality of numeracy (5.6).

I could go on but the point seems clear. The review of the QAA benchmarks for economics has taken the form of a limited exercise. The nature of its limits indicates the process has been conducted from within the narrowness of method and theory rather than has been oriented on the narrowness of method and theory. The whole is very clearly a set of minor modifications from within (rather than directed at) the received narrowness of the field.

\section{Conclusion: Better Benchmarks for a Different Kind of Economics}

By way of conclusion it seems constructive to ask: if a genuine reconstruction of the benchmarks takes as its point of departure the need to actively encourage what has not previously been the case (and explicitly recognize failures and challenge what has been the case), what might this look like? Though one might consider any substantive response here to be a UK affair it is worth again noting that the issues arising are not just UK issues. They may take a specific form in the UK but there are general processes at work. As such, any reconstruction of the benchmarks can be read as both specific to the UK guidance but also as general orienting statements for a different approach to economics. This is particularly so of the initial nature and context of economics section explored in some detail in the previous section. So, one might state a more fundamental reconstruction of the benchmarks as this:

In recent decades economics has placed too great an emphasis on a narrow range of ways of theorising and of conducting research and this has overly restricted the theoretical insights of economics, the explanatory focus of economics, the analytical skills of economists, the contributions of economists to society in general, and the nature of policy advice. In order 
to broaden the field it is necessary to reconsider how we conceive of economics, and it is also necessary to actively encourage previously under-emphasised aspects of the discipline through the way in which we teach economics and in terms of what we teach:

1. Economics is the study of social provisioning or the different ways in which psychological, social and material well-being are and can be achieved through an economy. An economy is a historical and dynamic entity and its construction necessarily involves institutions and an emergent political framework that fosters particular trajectories for that economy. An economy is embedded in an ecology and there are material limits to development that cannot be ignored and are central to the continued achievement of well-being. Deliberation is fundamental to informed decision making at a micro and macro level and so economics is also an ethical science. Economics is integral to political processes and so has implications for policy and for how citizens live. It is always also political economy.

2. In so far as economics is the study of the social provisioning process, its insights are based on different sets of theoretical commitments or emphases. There are then many different ways to approach an economic problem and many different ways to construct theory and pursue an economic investigation. Economics is therefore necessarily pluralistic. Historically it encompasses different schools of thought that consider economic problems from different points of view based on different foci, concerns and ultimate aims. Since economics is deliberative and economies can qualitatively change, then there is also an ongoing need to consider new kinds of theorisation to consider old problems in new ways, and new problems based on new insights. Economics is contested but this is not simply a data issue; it is also an issue of the consequences of the dynamics of different approaches to social provisioning. Pluralism is ultimately a commitment based on the recognized value for the vitality of the discipline of constructive engagement with different approaches to an economic problem. It is rooted in the complexity, contingency and malleability of social reality.

3. Social reality is an integrated whole and economics is one way of demarcating an aspect of that whole. Its insights ought then to cohere with those of other social sciences, and productive interchange between the disciplines is an important way each can both inform and temper the claims of the others. It is therefore important that economics considers the theories, critiques and methods of other disciplines rather than primarily transpose its modes of analysis onto the subjects of other disciplines. This is part of what it means to 
be effective in studying economic phenomena in their historical, political, social, institutional and international contexts.

4. A successful economics education produces well-informed, responsible and critically aware citizens able to contribute more effectively to deliberation regarding issues of social provisioning. It also produces more productive economic participants and effective economic analysts.

5. Economics is in the broad sense a realist science. It pioritises realism and relevance over precision. It recognizes that there are many methods that may provide insights into an economic problem. It recognizes that there are limits to the use of any given method. It recognizes that an effective economics education develops the ability of an economist to understand the limits and potentials of different methods and different ways of theorising. In so doing, it recognizes that the ability to construct theory, and evaluate and use methods, requires a framing context of critical awareness. That awareness necessarily requires all students to be versed in the history of economic thought and the progress of economic history. It is also enhanced by the reflexive skills provided by the philosophy of economics, including, for example, social ontology. Without these, model building, the use of given methods, and of quantitative and qualitative data can all too readily be misused.

\section{Acknowledgments}

Thanks to Ben Fine, Tony Lawson and Andrew Mearman for comments.

\section{References}

Association for Heterodox Economics. 2014. "Pluralism, heterodoxy and the prospects for a new economics curriculum.” Accessed 25 March 2015. Available at: http://www.hetecon.net/

Arnsperger, C. and Varoufakis, Y. 2006. 'What is neoclassical economics?' Post-autistic Economics Review no. 38: 1-8.

BBC. 2015. ”Teaching Economics After the Crash”, BBC Radio 4, broadcast January $4^{\text {th }}$. Accessed January $4^{\text {th }}$ 2015. Available http://www.bbc.co.uk/programmes/b04svjbj

Beggs, M. 2012. 'Occupy economics’, The Economists’ Voice 9, no. 3: 1-6.

Birdi, A. 2014 'Changing the subject', Royal Economics Society Newsletter, no. 166: 10-11 Boyer, R. 2013. 'The present crisis: A trump for a renewed political economy', Review of Political Economy 25, no. 1: 1-38. 
Carney, M. 2015. “Opening Remarks: One Bank Research Agenda Launch Conference.” Bank of England February 25 ${ }^{\text {th }}$, Accessed 25 March 2015. Available at:

https://www.youtube.com/watch?v=7hysEH_EdS4

Colander, D. 2005. 'The making of an economist redux.' Journal of Economic Perspectives 19, no. 1: 175-198.

Colander D. and Klamer, A. 1987. 'The making of an economist.' Journal of Economic Perspectives 1, no. 2: 95-111.

Colander, D. Holt, R and Rosser Jr, B. 2004. 'The changing face of mainstream economics.' Review of Political Economy 16, no. 4: 485-499.

CORE. 2014. 'New Teaching for Economics: The INET-CORE Project', Royal Economics Society Newsletter, no. 166: 11-15

Davis, J. 2006. 'The turn in economics: Neoclassical dominance to mainstream pluralism?' Journal of Institutional Economics 2, no. 1: 1-20.

Dow, S. 1996. The Methodology of Macroeconomic Thought Cheltenham: Edward Elgar

Dow, S. 1997. 'Mainstream economic methodology.' Cambridge Journal of Economics 21, no. $1: 73-93$.

Dow, S. 2012. Foundations for new economic thinking: a collection of essays Basingstoke: Palgrave Macmillan

The Economist. 2015 'Teaching Economics: The demand side, the economics curriculum is evolving but too slowly for some.' The Economist February $7^{\text {th }}$

Fine, B. 2013. 'Economics: Unfit for purpose.’ Review of Social Economy 71, no. 3: 373-389

Fine, B. and Milonakis, D. 2009. From Economics Imperialism to Freakonomics: The shifting boundaries between economics ands other social sciences London: Routledge

Fourcade, M. Ollion, E. and Algan, Y. 2015. 'The superiority of economists.' Journal of Economic Perspectives 29, no. 1: 89-114.

Fullbrook E., editor. 2008. Pluralist Economics London: Zed

Gabor, D. 2014. 'Learning from Japan: The European Central Bank and the European sovereign debt crisis.’ Review of Political Economy 26, no. 2: 190-209.

George, D. 2007. 'Consolations for the economist: The future of economic orthodoxy', Journal of Economic Surveys 21, no. 3: 417-425.

Hodgson, G. 2009. 'The Great Crash of 2008 and the reform of economics.' Cambridge Journal of Economics 33, no. 6: 1205-1221. 
INET. 2011 "Building a global community of New Economic Thinkers: Inaugural Annual Report 2010-2011” Accessed 25 November 2013 New York: INET [no active Url apparent, original Pdf available from author]

ISIPE (2014) “Open letter.” Accessed 20 March 2015. Available at: http://www.isipe.net/open-letter/

Keen, S. 2001. Debunking Economics London: Pluto

Keynes, J. 1921. A Treatise on Probability London: Macmillan

Klamer A. and Colander, D. 1990. The Making of an Economist Boulder Colorado: Westview Press

Knight, F. 1921. Risk, Uncertainty and Profit New York: Houghton Mifflin

Kreuger A. 1991. 'Report of the commission on graduate education in economics.' Journal of Economic Literature 29, no. 3: 1035-1053.

Lancastle, N. 2015. “It’s out! The revised UK economics curriculum.” Blog. Posted 31 January 2015. Accessed 11 May 2015. Available at: http://lancastle.blogspot.co.uk/2015/01/its-outproposals-to-revise-uk.html

Lawson, T. 2003. Reorienting Economics London: Routledge

Lawson, T. 2009. 'The current economic crisis: its nature and the course of academic economics.' Cambridge Journal of Economics 33, no. 4: 759-777.

Lee, F. 2012. 'Heterodox Economics and its Critics.' Review of Political Economy 24, no. 2: 337-351.

Lee, F. Pham, X. and Gu, G. 2013 'The UK Research Assessment Exercise and the narrowing of UK economics.' Cambridge Journal of Economics 37, no. 4: 693-717.

Lee, F. and Cronin, B. 2015. Handbook of Research Methods and Applications in Heterodox Economics Cheltenham: Edward Elgar

Leijonhufvud, A. 1973. 'Life among the econ.’ Western Economic Journal 11, no. 3: 327337.

Mearman, A., Shoib, G., Wakeley, T., and Webber, D. 2012. 'Does pluralism in economics education make better educated, happier students? A qualitative analysis.' International Review of Economics Education 10, no. 2: 1-26.

Milonakis, D. and Fine, B. 2009. From Political Economy to Economics London: Routledge

Morgan, J. 2009 'The limits of central bank policy: economic crisis and the challenge of effective solutions.' Cambridge Journal of Economics 33, no. 4: 581-608.

Morgan, J. 2014. 'Necessary pluralism in the economics curriculum: the case for heterodoxy.' Royal Economics Society Newsletter no. 167: 14-17. 
Morgan, J. 2015. 'The contemporary relevance of a Cambridge tradition: economics as political economy, political economy as social theory and ethical theory.' Cambridge Journal of Economics 40, no. 2: 663-700.

Morgan, M. and Rutherford, M. 1998. 'American Economics: The character of the transformation.' History of Political Economy 30, supplement: 1-26.

Negru, I. 2010. 'Plurality to pluralism in economics pedagogy: the role of critical thinking.' International Journal of Pluralism and Economics Education 1, no. 3: 185-193.

Olsen, W. 2012. Data Collection: Key debates and methods in social research London: Sage Post-crash Economics Society. 2014. 'Economics, education and unlearning', Accessed 20 March 2015. Available at: http://www.post-crasheconomics.com/

Pressman, S. 2013. 'The Review of Political Economy at 25: Past, Present and Future.' Review of Political Economy 25, no. 4: 533-543.

QAA. 2015a. "QAA debate signals fundamental change in the study of economics.” QAA Press Release, February $2^{\text {nd }}$ Accessed 14 March 2015. Seems to have been deleted from: http://www.qaa.ac.uk/newsroom Hardcopy available from author

QAA (2105b) “Subject Benchmark Statement: Economics Draft for Consultation.” QAA, January. Accessed 14 March 2015. Available: http://www.qaa.ac.uk/en/Publications/Documents/SBS-consultation-economics.pdf

Reardon, J. Madi, M. and Cato-Scott, M. 2015. Introducing a New Economics: Pluralist, Sustainable and Progressive London: Pluto

Spash, C. 2013. 'The shallow or the deep ecological economics movement?' Ecological Economics no. 93: 351-362.

Starr, M. 2014. 'Qualitative and mixed-methods research in economics: surprising growth, promising future.’ Journal of Economic Surveys 28, no. 2: 238-264.

Stockhammer, E. and Yilmaz, D. 2015. 'Alternative economics a new student movement', Radical Philosophy no. 189: 2-8. 